\title{
Los Manuales de Auditoría \\ (Su Estructuración)
}

\author{
Dr. Pascual Chavez Ackermann \\ Decano de la Facultad de \\ Ciencias Contables
}

\section{les}

Porquéemplear los manua-

La finalidad de un procedimiento consiste, como es conocido, en actuar de modo que las operaciones de naturaleza repetitiva se realicen siempre en la misma forma. La necesidad de garantizar una rígida uniformidad de tratamiento de las transacciones $\mathrm{y} / \mathrm{o}$ acciones periódicas tiene su razón de ser en algunos motivos fundamentales.

1. Asegurarse que sean constantemente respetadas las políticas empleadas.

2. Reducir los errores operativos.

3. Reducir el período de adiestramiento de los nuevos auditores.

4. Facilitar la introducción de los auditores en los nuevos trabajos.

5. Evitar que los cambios del sistema sean consecuencia de decisiones demasiado rápidas.

6. Facilitar el mantenimiento de un buen nivel organizativo.

Unicamente se tiene la garantía de un constante respeto de los motivos recién mencionados no sólo cuando hayan sido definidas con exactitud las etapas o procesos de la auditoría, sino también perpetuados en unos documentos o los que se pueda hacer referencia cada vez que se manifiesten dudas o vacilaciones. Estos documentos, según la terminología actual en uso, se llaman "manuales".

En esencia, un manual es expresión formal de todas las informaciones e instrucciones necesarias para operar en un determinado sector; es una guía que permite encaminar en la dirección adecuada los esfuerzos del personal operativo.

A la vista de esta definición, un manual adquiere la figura de un instrumento de control sobre la actuación de cada uno de lo auditores. Pero es también algo más, pues ofrece la posibilidad de dar una fisonomía más definida a la estructura organizativa de la institución, que va a perder su carácter nebuloso y abstracto, para tomar cuerpo en una serie de normas bien definidas. Sin querer hacer juicios demasiado categóricos, un manual correctamente redactado puede ser un valioso instrumentodirectivo.Se puede comprobar esto si consi- deramos que, aun siendo unos simples puntos de llegada, los manuales vienen a ser los caminos por los cuales discurre todo el aparato institucional. Es decir, son la manifestción concreta de una mentalidad directiva orientada hacia la realización sistemática de las diversas actividades.

Esta última afirmación resultará más clara si tenemos presente que la redacción de un manual requiere un conocimiento detallado del tema tratado (las etapas o procesos de auditoría, las políticas, etc.). Debe por tanto ir precedido de un minucioso trabajo deanálisisqueconduzca a la identificación de cada fase del proceso en cuestión. La consecuencia del trabajo de análisis, apenas merece repetirlo, es la identificación de todas las inconsistencias y todos los errores que afectan al proceso mismo.

Para poder adquirir, a buen título, el carácter de ropaje formal con el que se cubre la estructura organizativa, un manual debe aparecerdespuésdelacreación de la estructura y representar el sello que autentiza su eficiencia. Con ello no sequiereafir- 
mar de ningún modo que el tipo de organización establecido en un manual determinado no pueda ser variado, se quiere únicamente decir, que el manual sale garantizado hasta el momento en que se considere oportuno cambiarlo. Además que también el manual debe registrar las variaciones producidas.

En disparidad con las afirmaciones hechas hasta aquí, hay quienes sostienen, alegando diversos motivos, la inutilidad de los manuales. Las principales objecciones tienen su punto de partida en el costo que ocasiona su redacción, en que matan la iniciativa individual burocratizando los diversos trabajos, y en que (especialmente en las organizaciones menores) no son absolutamente indispensables.

Mientras que no negamos alguna validez a las dos primeras objeciones, disentimos decididamente de la tercera, ya que resulta evidente la utilidad de los manuales en las instituciones de todas las dimensiones.

La preparación del manual La preparación del manual es una operación caracterizada por su extrema delicadeza. La idea de poner por escrito los procedimientos (etapas) que componen el trabajo de auditoría pueden parecer, a primera vista, bastante sencilla.

La existencia de una serie de operaciones cuya racionalidad ha sido ya comprobada por una experiencia más o menos larga, puede en efecto inducir a pensar que su formalización en una serie de normas escritas no es fuente de inconveniente de ningún género.

La impresión es netamente equivocada. Lo comprueban diversas órdenes de consideraciones. Ante todo, no se puede dejar de constatar que, aunque se trate de recoger material ya existente, no faltan las dificultades, pues este material se encuentra diseminado por toda la empresa y a veces es absolutamente inexistente. Pensamos a este propósito, en los esquemas de flujo de las operaciones: podrán existir en el caso que la institución haya hecho en época reciente un análisis, general o parcial, de sus provios procedimientos. En caso contrario, deben ser formulados.

En segundo lugar, la descripción de cualquier procedimiento tiene que ir acompañada de todo el material ilustrativo necesario para exponer con la debida exactitud cada una de la fases operativas que lo componen (formas impresas, esquemas, diagramas, etc.). $Y$ ello requiere evidentemente un conocimiento detallado de los trabajos en cuestión, que se puede encontrar solamente en quien realiza o dirige estos trabajos, o en un especialista en análisis de los procedimientos. Por fín, un manual tiene que ser el instrumento operativo. $Y$ esto significa que tiene que ser formulado, escrito y encuadernado en función de las específicas exigencias de los destinatarios. Un manual poco claro, $\mathbf{o}$ peor aún complicado o incompleto, pierde en el momento mismodenacer cualquier valor como documento de referencia para resolver dudas o incertidumbres y está destinado a terminar su existencia en el fondo de un cajón o en un estante.

La lista de las dificultades que se encuentran para la prepara.

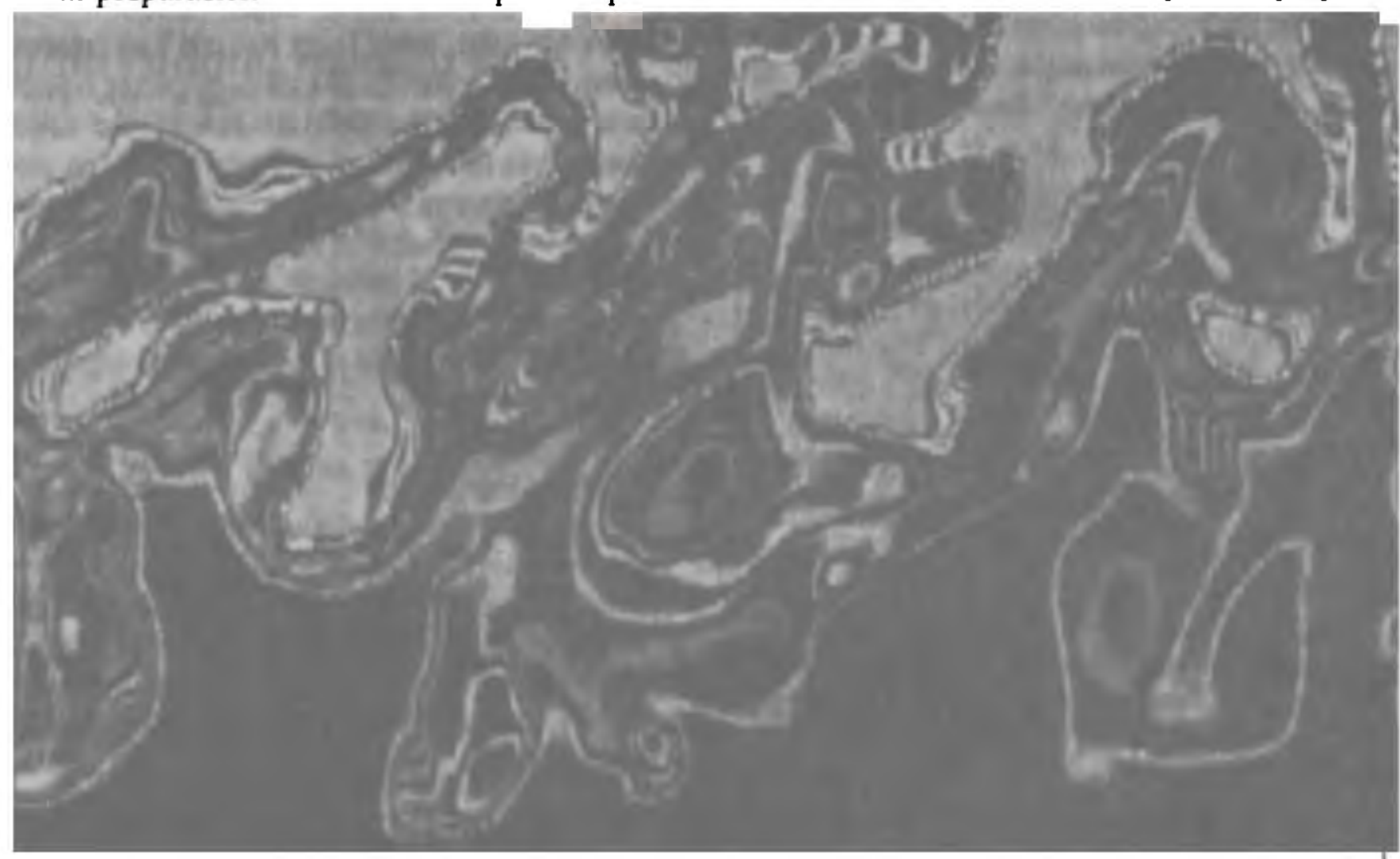




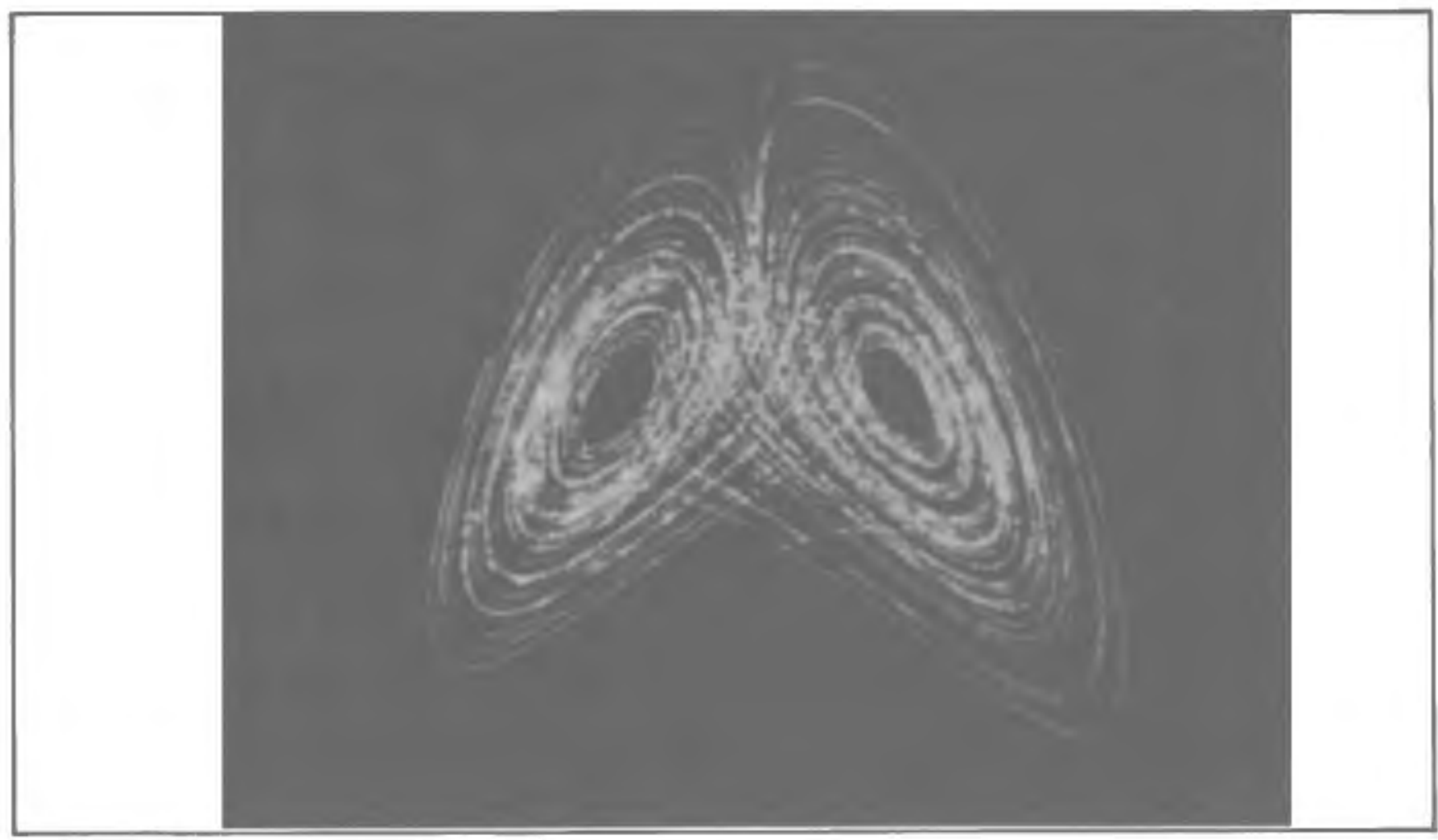

ción de un manual es como para poner a uno en guardia contra la excesiva presunción, pero es también suficiente para tranquilizar a quien tenga que afrontar este problema sobre la fácil superación de dichos obstáculos. Se trata también en este caso de evitar toda improvisación y de programar las cosas de acuerdo con un método que no está mal definirlo como científico. Intentemos entonces ver cuáles podrían ser las grandes líneas de una acción orientada a la confección de un manual. Los criterios de programación podrían ser los siguientes:

1. Informar a todos los empleados de la empresa que está en preparación un manual. En esta información va implícita una petición de colaboración y de sugerencias. Debeponerseel máximo cuidado en evitar que esta petición tenga un puro y simple carácter formal, sin esperanza de éxito desde el punto de vista operativo. La colaboración y la sugerencia de los empleados contribuyen mucho al buen éxito del manual, para que nos podamos permitir el lujo de relegarlos a un papel de segunda importancia. Ni qué decir, tiene también que ser tenida en alta estima la opinión de los jefes y gerentes.

2. Confeccionar una lista de los temas que deberán ser incluidos en el manual. Las finalidades que debe cumplir el manual, los costos que se quieren soportar en su confección, las políticas que la dirección quiere perseguir son elementos determinantes en la especificación de los puntos a incluir en el manual. La lista de materias debe ser expuesta en forma orgánica, subdividida en secciones $y$ subsecciones. Para dar a esta clasificación una mayor elasticidad es oportuno abrir una hoja por cada tema, de modo que sean muy sencillas las operaciones de corrección (inserción o eliminación de conceptos).
3. Nombrar a una comisión que se encargue de todo lo referente a la preparación del manual. Como hemos visto, la preparación del manual requiere un conocimiento específico de las materias tratadas. Merece por tanto la pena, por lo menos en los casos en que no exista una oficina especial, nombrar una comisión con el encargo específico de cuidar la redacción del manual. Esta comisión deberá estar compuesta por representantes de las diversas oficinas interesadas y presidida por un experto en problemas organizativos. La comisión debe asegurar las necesarias relaciones con los órganos $u$ oficinas periféricas y procurar la colaboración del personal que trabaja en ellos.

\section{Reunir toda la información} referente a cada tema incluido en el manual. El trabajo de preparación de un manual se da comienzo con la identificación de las fuentes del material a emplear. Tales fuentes deben, por 
tanto, ser clasificadas y numeradas, haciendo referencia a la clasificación previa de los temas. Se prepara así el esquema de realización del trabajo propiamente dicho, que para poderse hacer en forma racional debe ser terminado dentro de la fecha previamente establecida.

5. Preparar un primer borrador del manual, que se debe poner en conocimiento de las gerencias, de los jefes interesados y eventualmente de algunos auditores. La primera fase del trabajo de preparación de un manual termina con una primera redacción de la obra, que producida en un número limitado de copias, debe sercuidadosamente revisada, con el fin de introducir las eventuales modificaciones $o$ correcciones. Desde luego, las sugerencias que se aprovechen para la redacción definitiva pueden proceder de los más diversos niveles institucionales, tanto de las jefaturas, como de los empleados. Lo esencial es que el manual resultante esté a la altura de las finalidades que se desean alcanzar. Es preciso por ello que se preste atención no solamente a la sutancia de su contenido, sino tmbién a la forma en que está expuesto, refiriéndola al nivel medio de preparación de los destinatarios.

6. Someter la redacción definitiva del manual a la aprobación de la oficina especial. Un manual se perfecciona y se hace operante al recibir la aprobación de la alta dirección. Se obtiene cuando el manual, revisado en todos sus detalles, es presentado en su redacción definitiva a la dirección de la institución. Si se considera que han sido cumplidos los objetivos iniciales y que el manual tiene verdaderamenteun

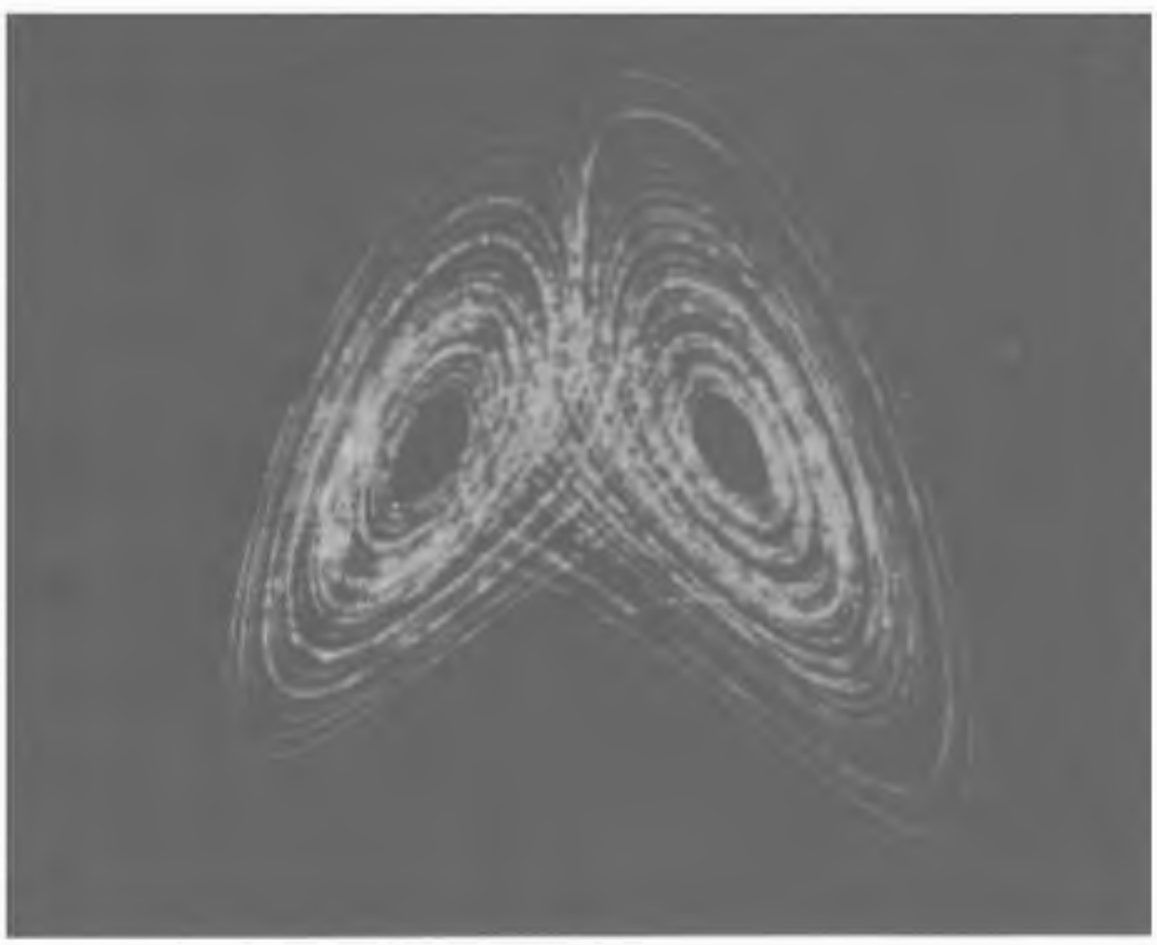

carácter operativo, el imprimir es una consecuencia automática de la existencia de los requisitos previstos.

\section{El contenido del manual}

Hemos visto de que forma se procede para la proyección y preparación de un manual. Es preciso ver ahora cuál tiene que ser en la práctica su contenido.

Si se quisiera hallar una regla a este propósito, se podría decir que un manual no debe contener más que los elementos estrictamente necesarios para el logro de los objetivos previstos y para el mantenimiento de los controles indispensables. Con ello es indudablequese ha definido una regla, pero no se ha especificado todavía cuáles son sus criterios de aplicación. Desde luego, es muy importante eldejar claroque un manual no debe estar sobrecargadode elementos superfluos que reduzcan considerablemente su valor opertivo. En otros términos, la sencillez y la profundidad deben ser los caracteres que inspiren su programación.
Sin embargo, sencillez y profundidad son dos términos cuyo significado más bien vago adquiere mayor relieve solamente cuando se desciende a cada una de las situaciones de la institución. A este propósito, mencionaremos solamente que son mínimas las informaciones necesarias para identificar los criterios de actuación y los dispositivos de control a que están sometidos; por el contrario, serán más completas las informacionesqueidentifican las operaciones más complejas. Análogamente, un número relativamente exiguo de informaciones puede permitir describir en forma satisfactoria las operaciones y los procedimientos existentes en una pequeña entidad. Crece el volumen del manual a medida que aumentan las dimensiones de la entidad y la complejidad de su estructura organizativa. En todo caso, es el concepto de esencialidad de lo que se desplaza y se adapta a situaciones cambiantes, mientras sigue invariable el criterio informador. 


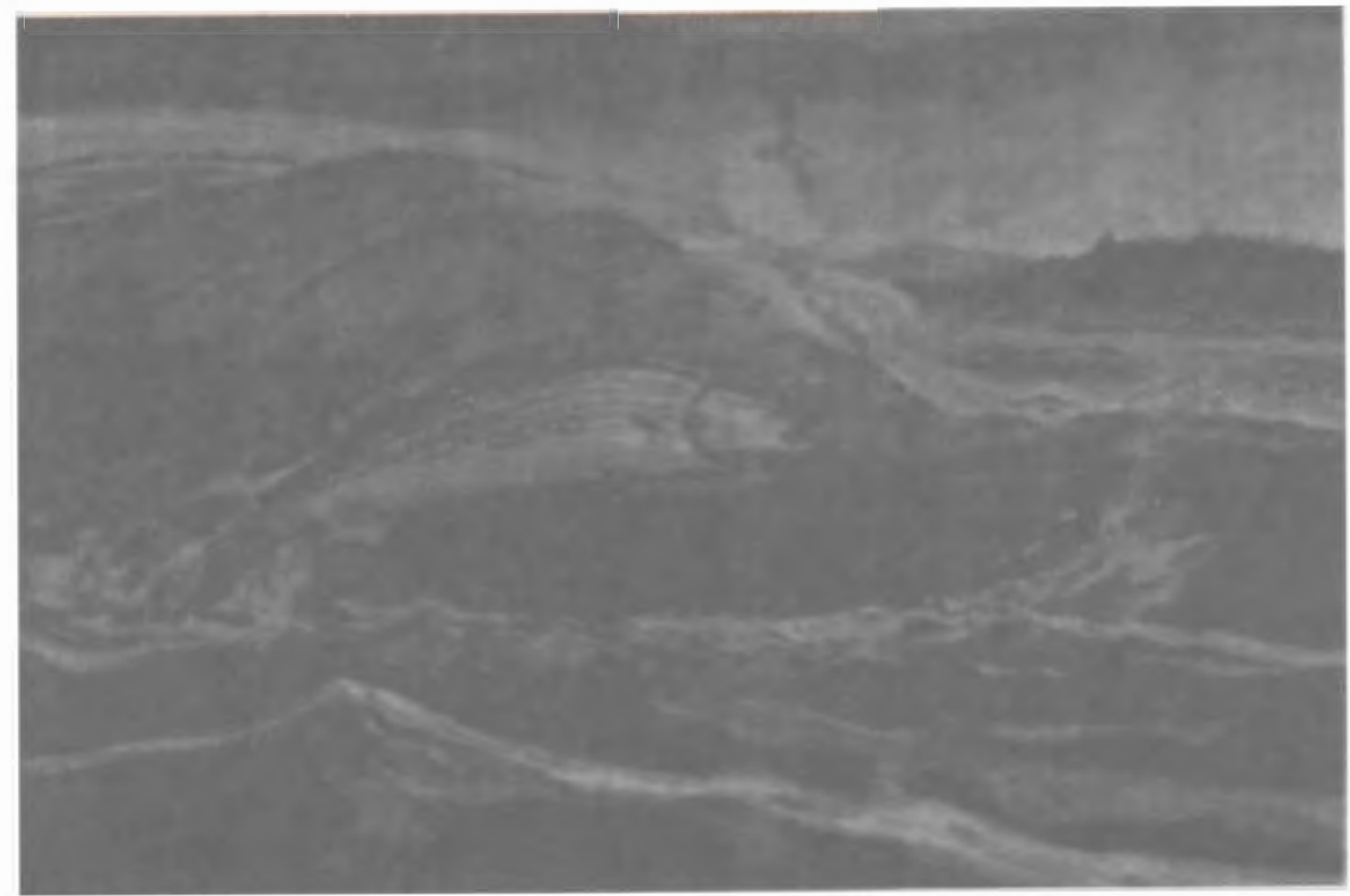

De estas breves anotaciones se puede comprender cuán difícil es abarcar en una fórmula única rodos los elementos que deben aparecer en cada sección del manual. La cosa no es factible porque son muy numerosas las combinaciones de situaciones potenciales que se pueden presentar a quien prepara el manual. Sin embargo, a título puramente informativo, se puedeenunciar una serie de elementos que deberían aparecer en todas sus partes:

1. Identificación del Tema

2. El número de procedimiento (o etapas)

3. La fecha

4. La indicación si sustituye anteriores disposiciones

5. Las aprobaciones

6. Los destinatarios

7. La numeración de las páginas

8. La descripción de los procedimientos

9. Los impresos empleados 10. Los impresos eliminados.

Los elementos que pueden aparecer en el manual

Merece ahora la pena que vea- mos en detalle cuál es el significado exacto de los elementos que hemos enunciado.

El tema a identificar debe estar siempre presente en cada parte del manual y debe ser repetido también, si es posible, en cada página que sigue a la del comienzo de la descripción del tema. Cada hoja correspondiente a cada tema debe ser por tanto identificada con un nombre o con el mismo. Se pueden dar por lo menos tres razones en apoyo a los dicho:

1. Es más sencillo volver a poner en su lugar las hojas que hubieran sido separadas del resto;

2. Es más fácil encontrar las páginas buscadas;

3. La búsqueda está orientada hacia el tema a identificar.

En el caso de operaciones particularmente complicadas, se puede encontrar un tema principal seguido de un tema secundario. Un ejemplo de clasificación de los temas de acuerdo con este esquema es el siguiente:
- tema principal: COMPRAS

- tema secundario: COMPRAS - ZONA SUR.

Naturalmente en el caso que las sucesivas subdivisiones tengan que ser llevadas más lejos, se podría pensar también en un tema de tercer nivel. Siguiendo con el ejemplo anterior, el tercer nivel podría estar representado por el concepto: Sede. En el manual podría aparecer entonces la siguiente fórmula:

COMPRAS

\section{COMPRAS ZONA SUR -}

\section{SEDE TACNA}

De todas formas, la clasificación de los temas debe ser programada no en función específica de la redacción del manual, sino teniendo en cuenta la estructuración de las etapas existentes en la institución o entidad.

Mención aparte merece, en fin, la idea ampliamente aceptada de emplear abreviaturas, lo mismo al tiempo de redactar los textos del manual como en la redacción 
de las fórmulas, la idea es sin duda válida. Las abreviaturas (pensamos en alguna de las más conocidas: CO-GE por contabilidad general AU-GU por auditoría gubernamental, etc.) ofrecen realmentedos ventajas por lo menos:

1. Reducen el tiempo de escritura y de lectura.

2. Se puede recordar fácilmente

La única recomendación que conviene hacer a este propósito es que las abreviaturas sean hechas de forma que conserven algún significado inmediato, como sucede en los dos ejemplos que hemos dado.

\section{La clasificación y la nume- ración de las etapas}

La clasificación de la etapas, encuentra inmediato reflejo en la clasificación de los temas comprendidos en el manual, es oportunoque esté acompañada y apoyada por un sistema racional de numeración. No estaría tampoco de más que cada una de las operaciones que componen una etapa estuvieran caracterizadas por un número.

Una numeración de las etapas y de las operaciones, programada oportunamente, ofrece estas ventajas:

1. Asegura una rigurosa uniformidad en la sucesión de las etapas descritas en el manual.

2. Facilita grandemente la tarea de localizar las instrucciones buscadas.

3. Facilita el cumplimiento del control, que resulta indudablemente más fácil si la sucesión de los temas está señalada con números en lugar de nombres.

La distinción de las etapas y de las operaciones efectuadas de acuerdo con una codificación numérica requiere, al mismo tiempo que una nomenclatura sistemática, una racional organización de todo el sistema de procedimientos.

Hablar de organización significa ante todo distribuir las etapas entre los grandes grupos a que corresponda; por ejemplo:

- Gobierno Central

- Gobiernos Locales

- Universidades

- Organismos Autonómos

- Etc.

Es preciso pasar luego a la especificación de las diversas etapas comprendidas en los sectores mencionados. En el sector Gobierno Central pueden configurar así las siguientes operaciones clave:

- verificar y analizar el presupuesto asignado

- determinar los costos de cada acción

- arqueo de caja (dinero, documentos y expedientes)

- analizar los asientos contables y su sustento documentario - examinar las anotaciones relativas a las existencias.

- etc.

Hay que hacer notar que los ejemplos citados son puramente indicativos, ya que la estructura efectiva decada clasificación puede variar de una institución a otra; pero conviene también poner de relieve que el mismo trabajo de numeración orgánica debe ser repetido en relación a cada sector especificado.

Dentro de cada etapa se puede buscar y ordenar luego las operaciones componentes $y$, si se quiere, se puede llegar hasta la determinación de las fases de realización de cada operación.
Después de terminado este trabajo sistemático de clasificación, es oportuno señalar cada concepto con un número, para facilitar su identificación, siendo aquí cuando se presenta el problema de la numeración.

Sobre este tema no nos detendremos durante mucho tiempo, ya que, tratándose esencialmente de un problema de codificación, lo creemos simple. Unicamente diremos que, teniendo en cuenta la estructura de la clasificación considerada, nos parece oportuna la utilización de un código de tipo decimal. En efecto, este código permite reflejar fielmente la articulación de los diversos asuntos en grupos y en cierto número de subgrupos. $\mathrm{Si}$ se quiere ilustrar el concepto con un ejemplo, se podría idear un sistema de clasificación, y por tanto de numeración, basado en este modelo:

- Grupos a que corresponden las etapas:

1. Auditoría

2. Personal

3. Compras (Licitaciones)

Etc.

- Subgrupos a que corresponden las etapas (agrupaciones funcionales de las etapas, referidas en nuetro caso al grupo principal

\section{Auditoria:}

1. Auditoría:

1.1 Examen general

1.2 Examen especial

1.3 Examen Proveedores

De esta forma la descomposición puede ser llevada hasta el infinito, extendiéndosea las operaciones, a las fases, etc. En la economía de un manual, el significado de una clasificación así estructurada consiste sobre todo 


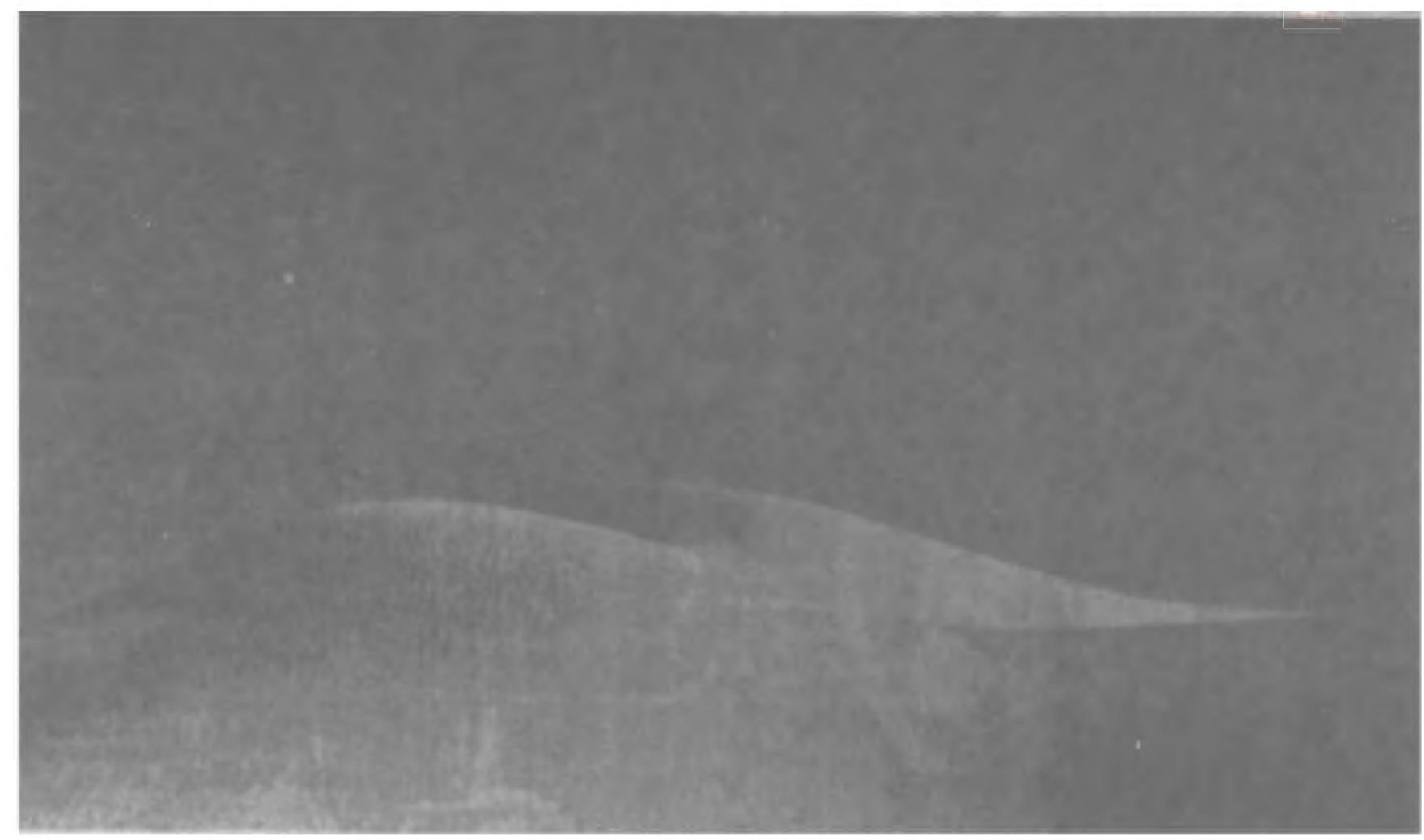

en permitir subdividir la materia tratada en capítulos, en títulos y subtítulos, facilitando considerablemente la búsqueda de referencias específicas.

Como complemento de todo lo manifestado, debemos añadir que el encabezamiento de cada capítulo, título, etc., debe hacerse indicando no sólo el asunto (por extenso o abreviado), sino también el número que lo caracteriza (código si lo hay).

El manual adquiere de esta forma una fisonomía verdaderamente orgánica y racional.

\section{Las fechas}

Entre los elementos cuya oportunidad es deseable en un manual, hemos indicado también las fechas, que permiten localizar en el tiempo la validez de un manual. Estas son:

1. La fecha de publicación

2. La fecha de entrada en funcionamiento.

En realidad coinciden rara vez.
Generalmente la fecha de publicación precede a la entrada en funcionamiento del manual, es decir, la fecha en que van a ser operantes las etapas descritas en el manual. Alguna vez puede también suceder que sea la fecha de entrada en funcionamiento la que preceda a la de publicación, pero el caso debe ser menos frecuente.

El motivopor el quedebe transcurrir cierto tiempo entre publicación y entrada en funcionamiento es que el manual es generalmente la expresión de un trabajo de racionalización que se hace dentro de las diferentes etapas. Las modificaciones subsiguientes a esta racionalización deben ser puestas en conocimiento del personal interesado antes de ser operantes, ya que aquél debe ser oportunamente adiestrado en el nuevo procedimiento. Todo eso requiere un período de tiempo, cuya duración coincide con el intervalo ya citado.

La necesidad de un periodo de ambientación aparecerá quizás con más evidencia si se piensa no en el manual redactado originalmente, que puede también reflejar una situación existente, sino en sus sucesivas actualizaciones. Estas representan efectivamente revisiones en los métodos de trabajo vigentes y requieren por ello un lapso de tiempo para que puedan ser aprendidas. El adiestramiento del personal no es, sin embargo, el único motivo que requiera un intervalo entre la fecha de publicación y la de entrada en funcionamiento. Considérese a este propósito si ocurren ciertos cambios, la dirección tienequedisponer de cierto tiempo para poder preparar todos lo instrumentos necesarios para el cumplimiento del trabajo en las nuevas condiciones. De ello que el conjunto de los dos motivos mencionados pueda actuar de modo que el intervalo tenga una duración que varíe desde unos pocos días a algunos meses, según la importancia de las innovaciones. En todo caso, la duración del período es función de 
dos factores:

1. La complejidad de las innovaciones;

2. La colocación temporal de estas innovaciones en los programas directivos.

Puede darse el caso que antes de llegar a ser operantes, sea necesaria la adquisición de algunos elementos materiales especiales. Puede también darse el caso que tales elementos materiales requieran el ingreso de empleados que sólo se pueden encontrar fuera de la institución. Bien se ve pues, que debe ser tenida en cuenta la incidencia de parecidos factores cuando hay que establecer la fecha de entrada en funcionamiento.

Puede ser también necesario un cierto período de tiempo entre la fecha de publicación y la fecha en que el manual llega a ser operante si las instrucciones son fácilmente asimilables. En este caso las instituciones descentralizadas territorialmente, emiten disposiciones que tienen que entrar al mismo tiempo en vigor en todas sus oficinas. Está claro que la fecha de entrada en funcionamiento dependerá de la seguridad que todas las gerencias y divisiones hayan recibido todo el material que les corresponde.

\section{La indicación de si sustitu-} ye anteriores disposiciones

Por lo general, la fecha de entrada en funcionamiento es suficiente para controlar la época en que ha sido efectivamente puesto en marcha determinada etapa. Sinembargo, no es suficiente para garantizar que la disposición a la que se hace referencia sea más reciente y por tanto la única válida en la actualidad. Justamente por este motivo, es oportuno que las últimas instrucciones lleven la indicación "sustituye a la anterior disposición entrada en funcionamiento el ..., que pierde todo valor y debe ser destruida". En este caso, es muy útil emplear un sistema de numeración del tipo que hemos presentado, ya que las referencias a disposiciones anteriores pierden todo carácter de aleatoriedad, evitando el riesgo de una equivocada destrucción de instrucciones todavía en vigor.
En efecto, la mención de sustitución no es siempre necesaria y puede ser evitada. Si la estructura organizativa de la institución funciona de manera satisfactoria, no puede faltar una serie de adecuados controles que den en todo momento la seguridad absoluta que los procedimientos actualmenteseguidos son las más recientes. El eventual descuido de algún auditor puede ser asimismo evitado sin una anotación que, en todo caso, podría escapársele.

\section{Las aprobaciones}

La indicación de haber sido dada la aprobación al procedimiento por parte de los órganos competentes es uno de los elementos que deben siempre figurar en las diversas partes de un manual. Este principio no ha encontrado ninguna oposición.

Orientaciones distintas se manifiestan, sin embargo, con respecto a las modalidades de expresión de la aprobación. Hay quien se inclina por la adición directa de la firma o firmas en las diversas copias del manual y

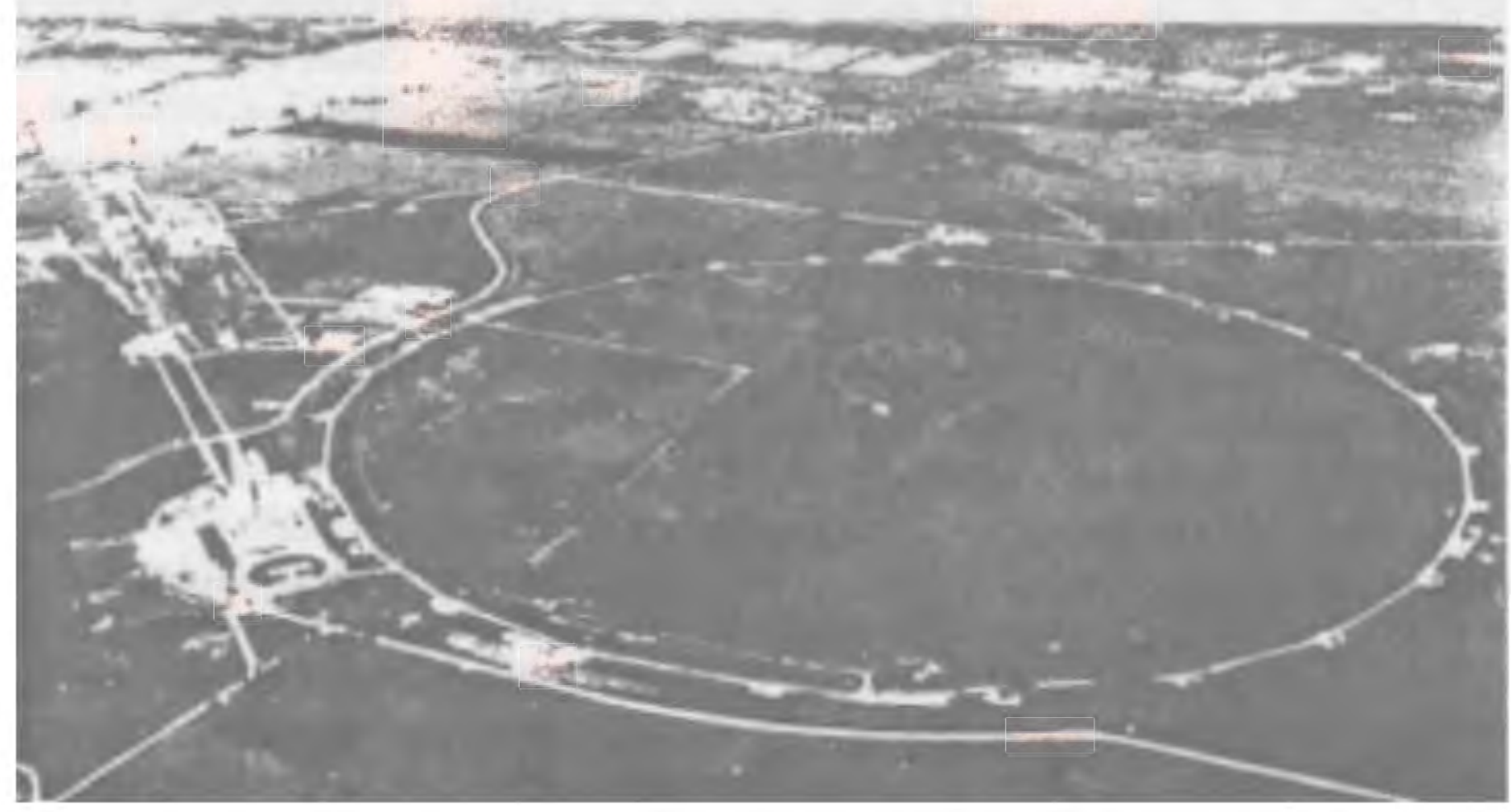




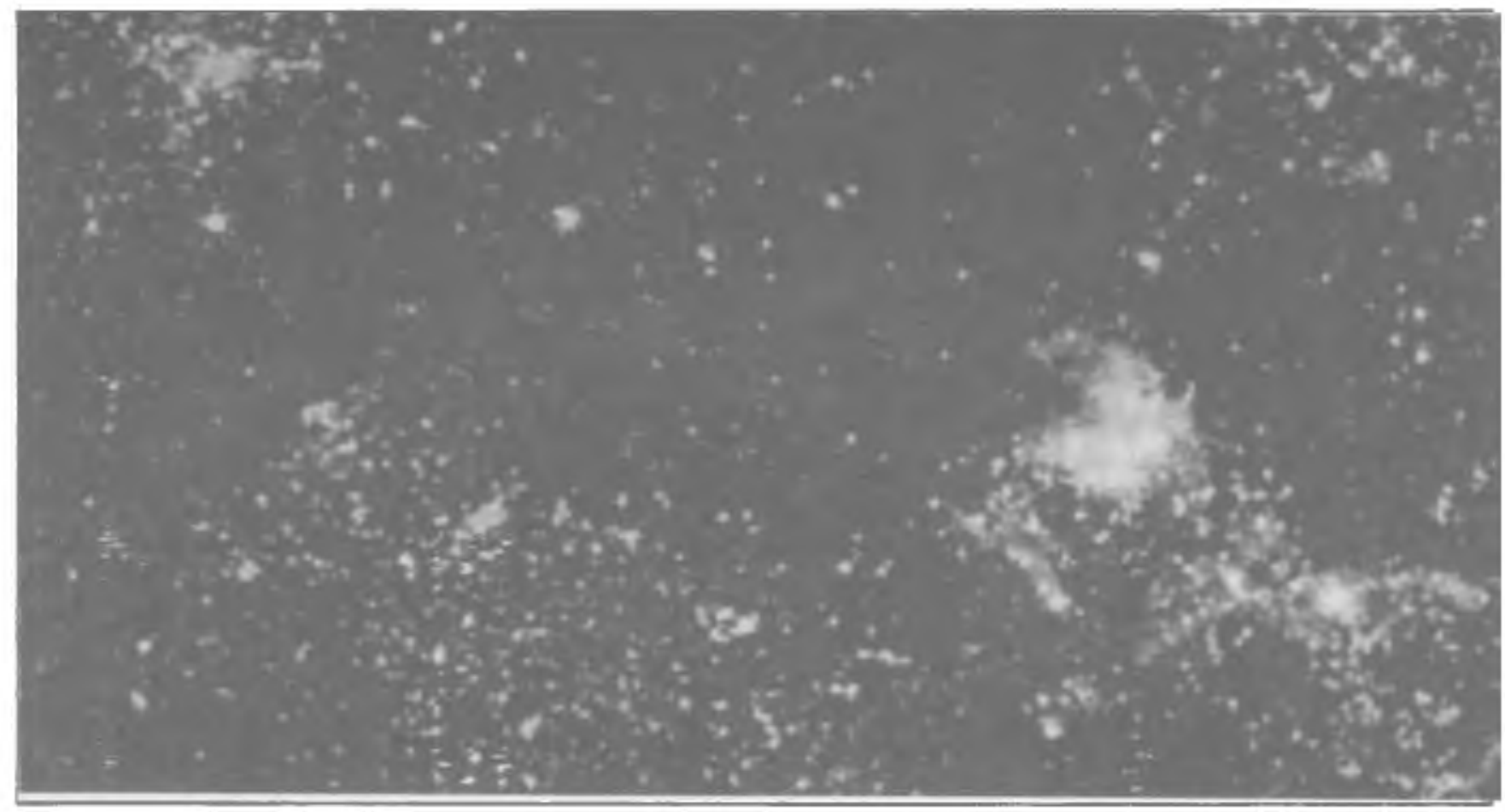

quien prefiere por el contrario poner en el manual la indicación mecanografiada de los órganos que han dado la aprobación. Se trata, como bien se ve, de una sencilla disquisición formal, aunque se ha podido constatar que la presencia física de una o más firmas en el manual sirve para dar más autoridad y fuerza a las disposiciones contenidas en el mismo.

De todas formas, lo esencial es la existencia de una aprobación que, para no dar origen a errores o discusiones debe expresarse siempre en forma escrita. En otros términos, se podrá discutir si la firma o las firmas deben aparecer en las copias del manual, pero sí es indudable que la aprobación debe ser firmada. Se hace entonces evidente que si se rechaza la primera solución, la firma deberá ser puesta en un impreso adecuado de aceptación. Es cierto que si la negativa a firmar el manual está motivada por la pérdida de tiempo que origina la adición de la firma en cada copia, es fácil contestar que la firma tiene igualmente un valor aunque se ponga el original solamente en la matriz de la cual son obtenidas las copias. Se trata de un método técnico bastante definido que merece ser señalado.

Falta ahora ver a quien corresponde la responsabilidad de aprobar un manual. Según la rutina corriente son los órganos de línea directamente interesados en la aplicación del procedimiento quienes deben asumir esta responsabilidad. Es decir, son los dirigentes de los sectores afectados por el procedimiento en cuestión, quienes deben aprobar sus modalidades de realización. La cosa no admite discusión, pues aunque se admita que la preparación del manual haya estado al cuidado de la dirección del trabajo de auditoría o del departamento de organización son siempre los responsables de la línea operativa los que deben expresar su aprobación y no los órganos del staff.
Los destinatarios del manual: criterios de distribución

El problema de la distribución de los manuales es de los más delicados, especialmente en las instituciones de grandes dimensiones.

Ante todo, conviene aclarar que un manual no debe ser distribuido íntegramente a todos los miembros de la organización. En particular es suficiente que el personal subalterno reciba únicamente las instrucciones que afecta al procedimiento en el que está interesado. Sólo los directivos, y tal vez los jefes de oficina, pueden recibir las ediciones completas.

Se sigue de aquí la necesidad de conocer por anticipado quienes serán los destinatarios de los diversos ejemplares, para poder dar disposiciones exactas sobre el número decopias que se deben imprimir y así evitar gastos inútiles. Además es necesario conocer los nombres de los destinatarios, para poder organizar convenientemente la distribución y 
asegurarse que cada interesado ha recibido la copia que le corresponde. A este propósito, es bueno preparar una lista donde los nombres aparezcan clasificados según los sectores a que corresponde. Numerando debidamente las copias del manual, se hace luego facilísimo el controlar si todos los destinatarios previstos tienen la suya.

Para facilitar posteriormente la consulta de un manual, es buena norma especificar en la primera página de cada instrucción cuáles son los sectores o las oficinas interesadas en su aplicación.

Esta indicación puede servir de control para asegurarse que todas las personas que se encuentren en la zona de trabajo indicada han recibido una copia de las normas.

\section{La numeración de las pági- nas \\ Cada página de un manual debe ser numerada para poder siempre controlar su existencia y la exactitud de su colocación.}

Los posibles criterios de numeración son, por lo menos, dos:

1. El basado en la numeración consecutiva de todo el manual.

2. El basado en la numeración independiente de cada una de las secciones del manual.

El segundo criterio es el que debe ser preferido, por su mayor flexibilidad. La consideraciónque hay que hacerse para la elección del criterio de numeración es bastante sencillo: un manual está a menudo sometido a revisiones, cuya consecuencia es la sustitución parcial de algunas páginas.
No siempre el número de las nuevas páginas coincide con las viejas, por lo que, o bien se crean vacíos, o se tiene un excedente. En todo caso, origina dificultades la numeración anterior. La única forma de superar el inconveniente, o por lo menos reducir su alcance, es fraccionar la numeración.

Con este objeto, se sugiere lo siguiente:

1. Numerar consecutivamente los grandes grupos a que corresponden los procedimientos, en la forma ya vista en el acápite respectivo.

2. Numerar consecutivamente dentro de cada grupo, las páginas respectivas, partiendo cada vezde 1. Al lado del número de la página conviene poner también el del grupo. Las páginas del grupo estarán según este criterio señaladas con los siguientes núme$\operatorname{ros} 1.1,1.2,1.3,1.4$, etc.

3. Indicar en la página de apertura de cada sección aquellas donde aparecen todas las notas decarácter general, como el asunto, las fechas, las aprobaciones, etc. Se debe reservar un espacio apropiado para la introducción de las eventuales variaciones.

4. Regular las eventuales inserciones en la forma siguiente:

a. Si el número de páginas que se deben insertar es superior al anterior o bien se puede retocar la numeración o dejarla sin variación repitiendo el número más elevado con la mención $A, B$, etc.: expliquemos este último caso con un ejemplo: supongamos que hayan sido modificadas las instrucciones obtenidas en las pági- nas 1.5 y 1.6 del manual, y que las nuevas normas ocupen cuatro páginas. Supongamos también que el número de páginas de la sección 1 sea superior a 6 . En este caso, las dos páginas en exceso pueden llevar los números $1.6 \mathrm{~A}$ y 1.6 B. Su presencia debe ser anotada en la parte inferior de la página 1.6 con una anotación de este tipo: "sigue en las páginas 1.6 A y 1.6 B", o bien "ver las páginas $1.6 \mathrm{~A}$ y $1.6 \mathrm{~B}$ ". La variación del número total de páginas debe ser además mencionada en la página de apertura de la sección.

b. Si el número de páginas que se deben intercalar es inferior al anterior, se puede también en este caso obien retocar la numeración o dejarla sin variación. Pero conviene anotar, en la página que precede inmediatamente al vacío, una inscripción de este tipo: "la página (o las páginas)... ha sido eliminada" y registrar la variación cuantitativa en la página de apertura de la sección.

Razones de oportunidad sugieren que la puesta al día de los manuales se haga directamente por el órgano que se encargó de su redacción original. Siempre que se produzcan variaciones, se debería por tanto revisar los manuales a los que afecten las mismas, y ponerlos al día en debida forma. Esta gesión, aunque produce una sobrecarga de trabajoal órgano que se ocupa de los manuales, asegura en la forma más absoluta la perfecta integridad de los mismos y su precisión.

Descripción de las operaciones. El manual y el adiestramiento

El núcleo central de un manual lo constituye la descripción de las operaciones tratadas en el 


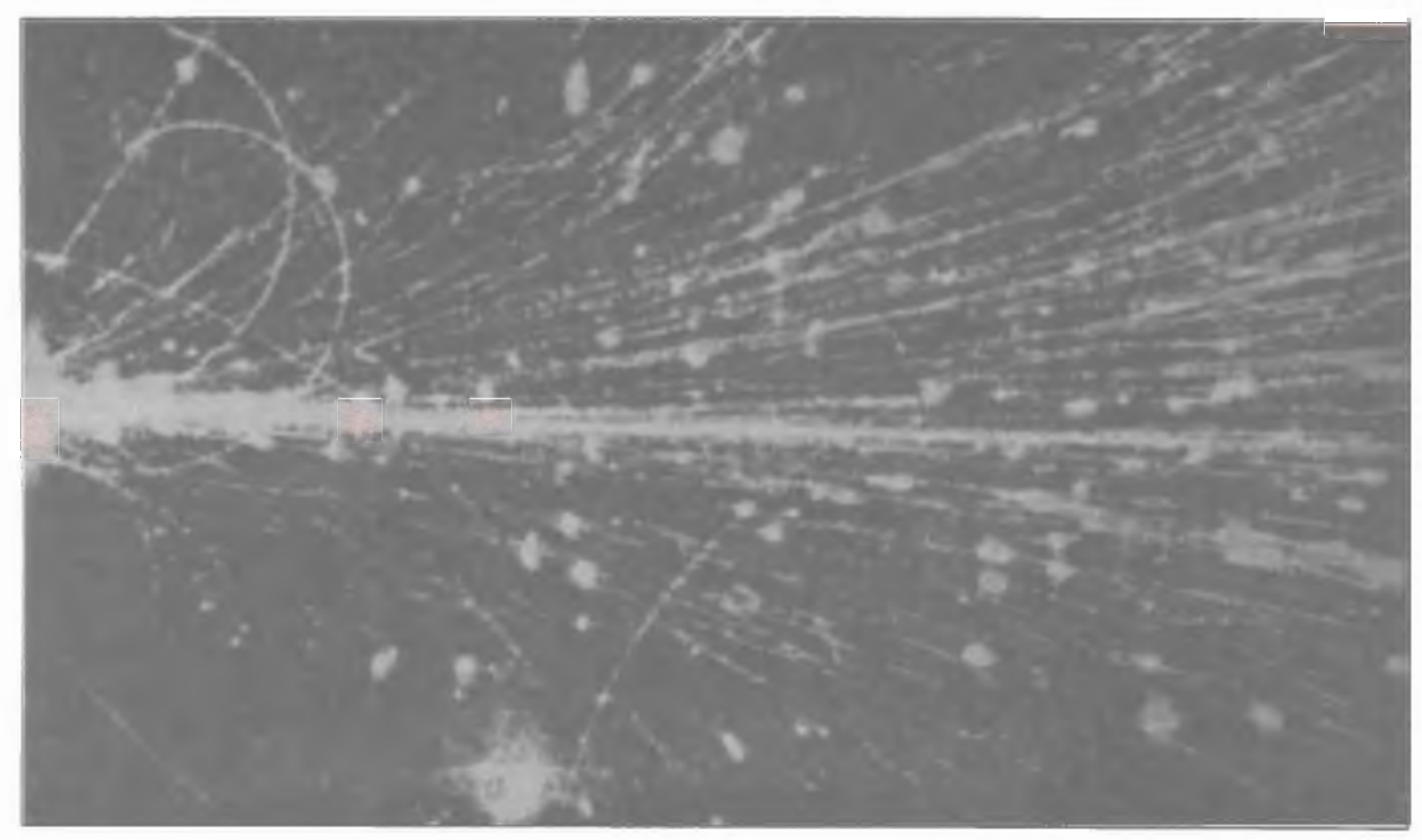

mismo. Los elementos vistos hasta ahora tienen, si se quiere, un carácter accesorio y complementario y cumplen con la única finalidad de facilitar el acceso a la parte verdaderamente esencial de la obra. Pero el manual encuentra su verdadera y definitiva razón deser en la descripciónde las operaciones. Parece por ello lógico que a la redacción de esta parte se le dedique la mayor atención y que se intente hallar alguna regla a este propósito.

Antes de describir los criterios en que se debe inspirar la redacción de un manual, creemos no estará de más puntualizar cuáles son los objetivos que se persiguen al formalizar por escrito la realización de las operaciones. Los objetivos mencionados son, como hemos visto, por lo menos dos:

1. La reducción de los costos de adiestramiento.

2. El mantenimiento de un buen nivel organizativo.

Sobre los costos de la capacitación, se podría hacer un largo razonamiento. Pero lo que interesa únicamente es decir que tales costos son variables, aunque cada vez más elevados. La variabilidad es función de diferentes factores, los principales de los cuales son: el tiempo gastado por el instructor/profesor y por todos los que intervienen en la capacitación, la cantidad de producción dejada de hacer por parte del entrenado, etc. Con más generalidad, se puede decir que la variabilidad está directamente relacionada con la duración del proceso de capacitación.

En esta situación fácilmente se ve que cualquier medio que contribuya a esta reducción será fuente de considerable economía. Un manual es justamente uno de tales medios, pues la posibilidad de disponer de un soporte en el que esté escrito con claridad de términos el trabajo que se ha de realizar, se resuelve en una reducción del período de capacitación. Naturalmente, la utilidad del manual será tanto más elevada cuanto mayor sea la complejidad del trabajo.

El mismo razonamiento que se aplica a la capacitación de los nuevos auditores, tiene también validez para la capacitación en los nuevos trabajos confiados al personal ya existente. Desde luego se puede decir a este propósito que la existencia de un manual facilita el traslado de los auditores de un trabajo a otro.

\section{El manual y el nivel organizativo}

Los manuales representan, además, el sello de garantía puesto a la estructura organizativa existente. Para asegurarse de ello, no hay más que considerar que un sistema funcionará perfecta- 
mente si se apoya en una estructura organizativa que incorpore una clara definición de las líneas de autoridad y de responsabilidad. En este sistema, los procedimientos son los principios fundamentales en que está basado el control de la estructura. En efecto, en ellos toman forma concreta las relaciones de autoridad y responsabilidad y se hacen explícitos. (Delegar para que cada cual en su nivel decida).

No hay duda por tanto que un procedimiento, al tener que cumplir una tarea tan importante, haya de ser aplicado exactamente en los mismos términos que ha sido ideado, sin alteración ni deformaciones. El manual es el instrumento que permite alcanzar esta finalidad. Fija el procedimiento en forma inequívoca, sin posibilidad de falsas interpretaciones, y obliga a quien lo emplea a adaptarse escrupulosamente a las instrucciones contenidas en el mismo. (Sin chocar con la normatividad vigente).

Es difícil que pueda ser obtenido igual resultado si las intrucciones son transmitidas verbalmente, porque ésta es la forma que más se presta a malas interpretaciones y que ofrece siempre una escapatoria en la frase: "¡No había entendido bien!".

\section{Cómo debe ser estructurado el manual}

Los dos objetivos que justifican la preparación de un manual, vinculan en forma determinante los criterios que han de regir en su redacción.
Debiendoser el manual un instrumento para capacitar al personal y una guía para la mejor comprensión de la estructura organizativa de la institución, se puede deducir que deberá poseer las siguientes cualidades:

1. Sencillez

2. Perfección

3. Equilibrio

La sencillez es un requisito fundamental, especialmente si se pretende realizar con el manual una acción de capacitación. Consideremos que la sencillez posee por lo menos tres virtudes:

1. Facilita la lectura de las instrucciones

2. Elimina la posibilidad de erróneas interpretaciones

3. Reduce la dispersión de esfuerzos

Naturalmente, la sencillez debe encontrar su necesario complemento en la perfección y el equilibrio. Perfección significa que no ha sido omitido ningún aspecto del problema examinadoyqueha sido plenamentecumplida la función informativa del manual. Equilibrio quiere decir que no existen desproporciones entre las diversas partes del manual y que los criterios de redacción de sus diversas secciones son siempre los mismos.

Concedida la importancia que merecen a estas tres características que deben inspirar siempre la redacción de un manual, falta por ver cuáles son los otros factores que determinan su aspecto exterior. Queremos referirnos con ello a:

1. El tipo de encuadernación

2. El procedimiento de reproducción de las diversas copias

3. El tipo de ordenación de las hojas

Los criterios que deben presidir la encuadernación de un manual tienen que ser homogéneos para todas las páginasquelocomponen. Conviene emplear especialmente máquinas de última tecnología cuyos caracteres se puedan leer fácilmente, que el espacio entre líneas esté suficientemente distanciado (por lo menos dos a tres espacios) y que las dos márgenes sean bastante amplias: el de la izquierda para permitir la fijación de la hoja en el archivador y el de la derecha para permitir al usuario del manual que ponga alguna breve anotación. El problema del margen se resuelve generalmente usando hojas que lleven preparado con una marca el recuadro libre para la redacción.

Las hojas obtenidas de esta forma tienen que ser luego unidas y encuadernadas. Se debe rechazar a priori el sistema de encuadernación en forma de libro, por ser demasiado rígido y no permitir sustituciones eventuales. Es mucho mejor unir todo en los llamados archivadores de hojas móviles, asegurándose que cada manual esté protegido por tapas rígidas. Se hace así mucho más fácil el cambio de las hojas viejas por las que venga a sustituirlas. 